\title{
Designing Capacity Synchronization within the Regeneration of Complex Capital Goods
}

\author{
Thorben Kuprat*, Peter Nyhuis \\ Institute of Production Systems and Logistics, Leibniz University of Hanover, Germany
}

Copyright $(2016$ by authors, all rights reserved. Authors agree that this article remains permanently open access under the terms of the Creative Commons Attribution License 4.0 International License

\begin{abstract}
Regeneration service providers who are conducting maintenance, repair and overhaul (MRO) tasks in the field of complex capital goods face strong market-based requests like short delivery times and a high schedule reliability. Further they have to deal with uncertain workload information and high load fluctuations caused by different damages. In order to cope with these demanding challenges a holistic planning and control performance that includes all different regeneration processes is necessary. A main lever for planning and controlling internal supply chains is represented by the tasks of capacity synchronization. There are several so called design options available for synchronizing capacities. These design option influence the logistic performance and will help the service provider to reach their goals in terms of customer satisfaction.
\end{abstract}

Keywords Regeneration, Capacity Synchronization, Logistic Performance, Logistic Costs

\section{Introduction}

The regeneration of complex capital goods is subject to special requirements that make these processes different to common production environments [1]. Besides common competitive factors like high quality products and low prices short throughput times and short delivery times towards the customer have to be realized by regeneration service providers. One focus of the Collaborative Research Centre 871 "Regeneration of Complex Capital Goods" is the planning of regeneration processes. Planning regeneration processes is being complicated because the damage extent and with that the work load for each regeneration order is not known until the complex capital goods is being diagnosed at the regenerations service providers site [2]. A reliable production planning and control is therefore essential. In order to guarantee a high logistic performance regeneration service providers have to synchronize their capacities with the existing workload. Different options of synchronizing capacities and therefore different options for designing the regeneration process are applicable. Regeneration service providers have to consider the interdependencies of options and their effects on the logistical performance.

In general, capacity synchronization options can be implemented within the actual regeneration process where value-adding processes are being conducted as well as within the pool management. All capacity synchronization options and especially their combinations have a direct impact on the key process of the regeneration - the reassembly [3]. This converging point is situated at the end of the regeneration processes and can be seen as the final value adding step within the company's' internal supply chain before the goods are delivered to the customer. In order to guarantee high schedule reliability at the end of the supply chain, parts for a reassembly order have to make it to the reassembly on time as well as simultaneously to each other [3]. The configuration of capacity synchronization options directly affects the on time and the simultaneous allocation of parts at the reassembly. For an efficient execution of capacity synchronization tasks, a holistic overview of capacity synchronization options is necessary as well as key figures that help the user assessing different configurations. An approach for dealing with uncertain information within capacity planning includes a damage library [4]. A lot of feedback data is necessary and the effects on the reassembly are not directly derivable. Due to several existing supply processes and the resulting planning complexity a model that illustrates the impact of different synchronization configurations is needed. Within this paper, different options for synchronizing capacities are discussed and an approach for evaluating the configuration of options is introduced.

\section{The Regeneration Process for Complex Capital Goods}

Complex capital goods are characterized by multiple parts that show several functional interdependencies. Examples of products that belong to the group of complex capital goods are aircraft engines, stationary gas turbines, locomotive engines and wind turbines [5]. As these goods are damaged during their operation and as there are usually of high value 
the goods owners strive to regenerate these complex capital goods [6]. For most complex capital goods regular safety checks and maintenance processes are prescribed by law or internal standards.

The main objective of regeneration processes is to restore the regeneration good and to meet the customers' demands in terms of delivery times and product quality. Furthermore, regeneration is processed in order to ensure completely new life cycles for complex capital goods. [7, 8, 4] While the remanufacturing of products is processed for an anonymous market, the regeneration goods belong to the customer during the whole regeneration process [7].

A regeneration process can be separated into a disassembly section, a refurbishment section as well as a reassembly section [9]. Following the reassembly, quality ensuring processes are necessary. A detailed documentation about the activities throughout all processes is often mandatory. Within the disassembly, all incoming regeneration goods get dismantled. Different levels of disassembling are possible. The chosen disassembly level depends e.g. on the expected damage extend or the on the customer's demands. As some of the single parts are getting refurbished in the next steps, a non-destructive disassembly is necessary [10]. After the good is dismantled a part-specific diagnose is processed. Again, the use of non-destructive diagnosing methods is necessary [8]. Diagnosing parts is the first step within the regeneration section. Following a detailed diagnose and possible coordination processes with the customer about handling activities workloads for the following refurbishment steps can be assessed. Subsequently, the parts will be regenerated. Different value-adding manufacturing steps like welding, soldering or milling are possible.

Within the reassembly section the regenerated parts are getting assembled again. If single parts have to be replaced by original parts, e.g. due to non-repairable damages, parts that are on stock can be allocated as well. Therefore, reassembly processes are characterized by converging material flows (see figure 1). It is because different material flows come together within this process step that the necessary parts for a reassembly order need to be coordinated precisely. Three general material flows can be distinguished. The reassembly is supplied by the regeneration, by a pool of original and already regenerated parts as well as by parts that are procured. Only if all parts get to the reassembly on time at simultaneously the actual value-adding reassembly process can start on time, capital tie-up can be minimized and schedule reliability can be assured. Next to the pool for original parts two other kinds of spare parts can be hold on stock. A pool for damaged parts and one for already refurbished parts.

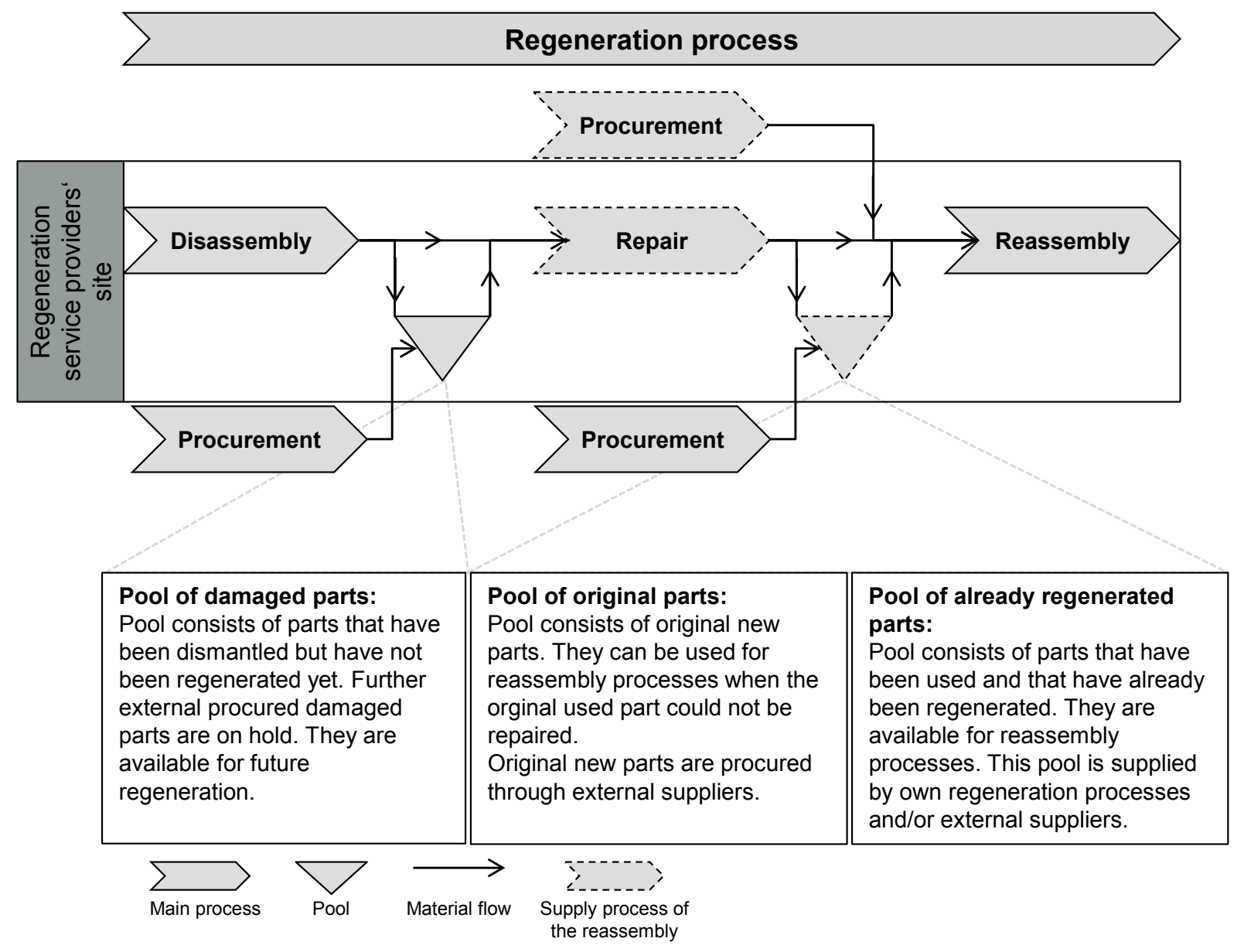

Figure 1. Core elements of a regeneration process (according to [11], [12]) 


\section{Capacity Synchronization within the Regeneration}

Synchronizing capacities is a major task within the planning and control process of regeneration supply chains. Main objective of the capacity synchronization process is to guarantee a certain logistic performance within the internal regeneration supply chain by matching capacities with workload. When talking about capacities two different kinds have to be distinguished. The first kind is represented by the machinery whereas the other kind of is represented by the personnel capacity. A regeneration orders workload is mainly determined by the kind and by the extent of damage as well as by the technical possible repair process. With synchronizing workload and available capacities delivery dates can be met and customer satisfaction can be sustained.

\subsection{Capacity Synchronization Options}

In general two procedures of how to execute capacity synchronization exist. The personnel or machine capacity can either be adjusted to the existing work load (capacity adjustment) or the workload can be aligned to available capacities [13]. In the first case the workload over time is fix and the degree of freedom for adjustment are the capacities.
An extra shift or additional overtime hours can be established to raise the personal capacity and to match the capacity profile with the workload profile. The overall machine capacity can, for example, be influence by purchasing a new machine. In the second case capacities can be seen as fix whereas the scheduled work load is the lever for aligning. Two more detailed categories have to be distinguished here. The workload peaks can be reduced by assigning the critical orders to other companies (load adjustment). By doing so, the workload does not have to be handled within the regeneration service providers' site. Or the workload peaks can be reduced by shifting the critical orders forward or backward (load levelling). In this case, workload peaks are spread over the planning horizon in order to match the workload with the available capacities.

An overview of possible capacity synchronization options gives fig. 2. In fig. 2 main capacity synchronization options that are ascribable to the field of production planning and control can be found. Other options for synchronizing capacities, e.g. due to merging and acquisition actions in order to increase the capacity level or due to more efficient marketing actions for an increasing workload are generally conceivable but they do not belong to the tasks of production planning and control departments and are therefore not included.

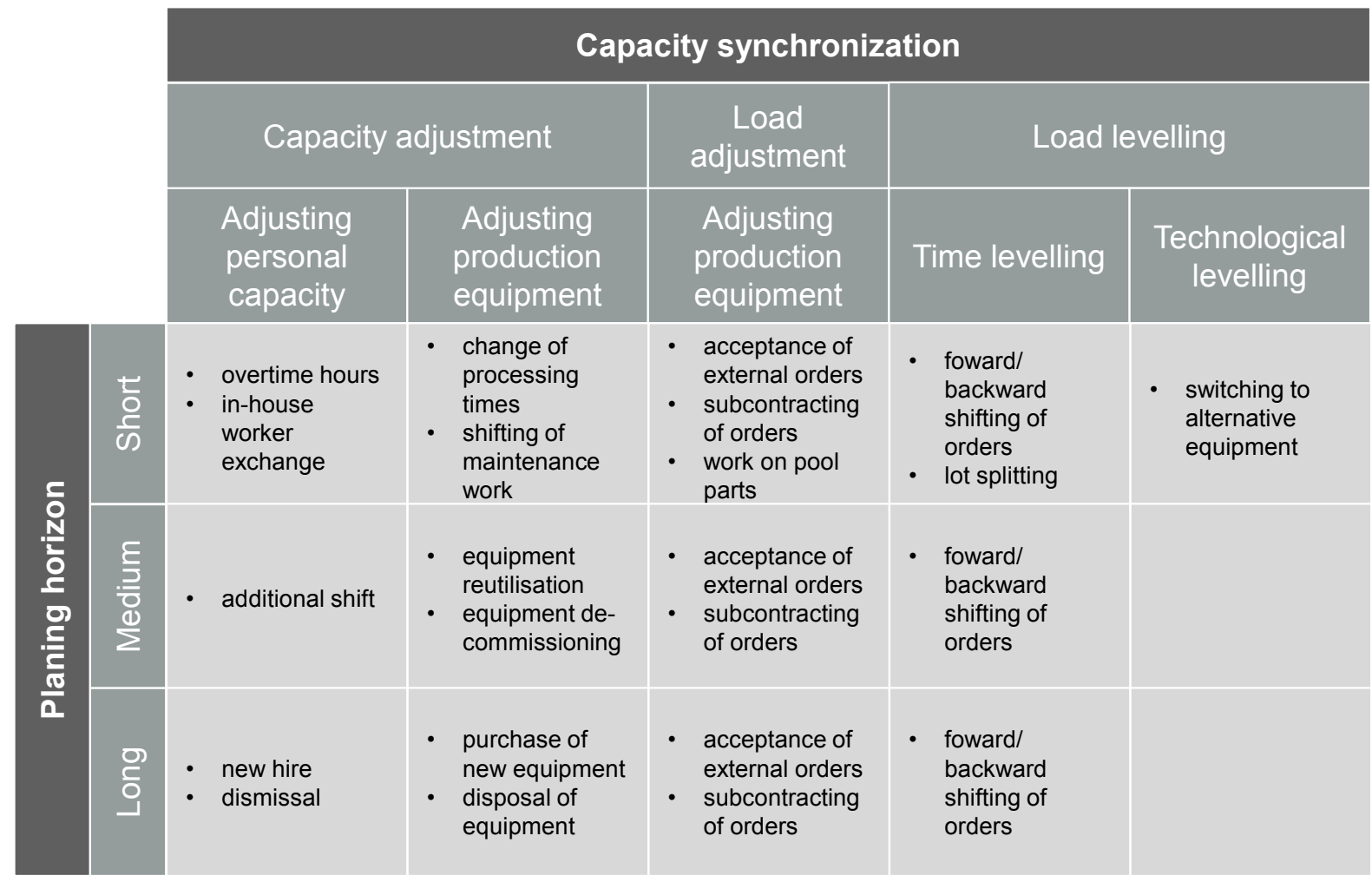

Figure 2. Capacity synchronization options for the regeneration (according to [13], [14]) 


\subsection{Assessing Capacity Synchronization Options}

When deciding about design options for capacity synchronization different criteria have to be considered. An important criterion is the minimum installation time [15]. The minimum installation time represents the time span for how long a possible design option needs to be established. Pulling forward regeneration orders belongs to the kind of options that have a very short minimum installation time. Increasing the personnel capacity due to new hires is a capacity synchronization option that, in general, lasts for a long time.

Another important criterion for evaluating the capacity synchronization option is the time span from when the service provider decides to establish a certain option until the option is finally realized. This time span is the reaction time and includes preparation processes that are essential for the options implementation [15]. It is evident that new hires usually come along with a longer reaction time than introducing overtime hours.

Both criteria, the installation time as well as the reaction time, can be combined to a key figure that describes the flexibility of the capacity synchronization option.

It is further evident that the minimum installation times and reaction times for one explicit capacity synchronization option differs from company to company. Overall the assessment depends on the specific application and company specific conditions.

Besides flexibility, several other assessment criteria have to be considered for the execution of capacity synchronization. Especially when carrying out synchronization with personal capacity adjustment options workers' qualifications have to be dealt with during the implementation process. When considering the purchase of machine capacity, investment costs and amortization rates have to be taken into account as well as expenses for adjusting planning and control processes. The following list summarizes main criteria that can be used for the evaluation of capacity synchronization options.

- minimum installation time

- reaction time

- installation costs

- expenses for adjusting processes

- expenses for developing workers' qualifications

All different capacity synchronization options all have an impact on capacity levels, workload levels and workload schedules. With that all options have in common, that they influence the regeneration supply chain's logistical performance. The impact is visible when looking at the mean values and deviations of the schedule reliability.

\subsection{Configuration of Capacity Synchronization Options}

It is evident, that different synchronization options can be processed at the same time. In order to guarantee a high logistic performance, the interdependencies of these options and the overall effect on logistical key figures have to be considered.

Next to synchronization options within the long- and midterm planning horizon the forward and backward shifting of orders plays an important role. This kind of synchronization option has a direct impacted on the missing part situation of reassembly processes as it delays or pulls forward orders. As the regeneration good is dismantled and multiple parts have to be regenerated the forward and backward shifting needs to be processed for all parts of a single regeneration order. When e.g. a backwards shifting due to an interruption needs to be processed a rescheduling is necessary for all parts that belong to the affected order. The new starting time for processing the explicit component at each work station $\left(\mathrm{TS}_{\text {new }}\right)$ and therefor the time change within the work stations load profile can be determined by the following equation:

$$
T S_{\text {new }}=\left(T S R_{\text {plan }}+T I\right)-\sum_{i=n+1}^{\text {number } W S} T I O_{\min , i}-\sum_{i=n}^{\text {number } w S} T O_{i}
$$

$\mathrm{TSR}_{\text {plan }}$ is the plan start time of the reassembly process whereas TI stands for the time of interruption. TIO is the interoperation time that includes waiting and transportation times between two working stations and TO represents the actual operation time. The sums go up to the number of working stations (number WS) that a single component has to pass until it reaches the reassembly. With that new priorities can be given and a new processing sequence can be derived. Even though the parts will get to the assembly with a delay they will still get there simultaneously and therefore minimize the negative impact of the interruption on the logistical performance.

In opposite to common production processes the regeneration service provider has the possibility to use the available parts within the pools in order to influence the workload (see figure 1). It often depends on the customer's specifications if pool parts can be used for a specific regeneration order. The main levers for the regeneration service provider are the service level of the parts that can be hold within the pools and the average stock level. In times of low utilization they can start processing pool parts that have not been regenerated yet in order to increase utilization within the regeneration process. Further, regeneration service providers can use the pool parts for adjusting the load level and minimize peaks within the work load profile. For this, they can pick a damaged part that will need fewer repairs that the original damaged part.

\subsection{Evaluating the Configuration of Capacity Synchronization Options}

As the reassembly depicts a central process step within the regeneration supply chain where different material flows come together, it is essential to measure the supply chains logistical performance at this point [3]. The synchronization options that are carried out will directly influence the supply situation at the reassembly process. The impact is visible 
when looking at the missing part situation of reassembly. A high missing part situation indication an insufficient coordination of the supply processes and often results in a high schedule deviation towards the following customers [3]. The so-called supply diagram (see figure 3 ) can be used for evaluating the influence of design options on the logistic performance.

The supply diagram is based on the schedule deviations of the supply processes [3]. The schedule deviations are weighted with the parts' value. By aggregating the schedule deviations of all supply processes an input curve as well as a so-called completion curve can be derived. By comparing these curves a key figure called disrupted WIP (work in progress) can be determined. This stock of disrupted WIP builds up when e.g. nine out of ten parts have to wait for the last part to arrive at the reassembly. Once all parts have arrived the actual reassembly process can start. When considering different capacity synchronization options within the value-adding regeneration process and within the pool management different input and completion curves will occur as these options directly influence schedule deviations. Capacity synchronization options have to be implemented in a way that the input curve and the completion curve of the supply diagram are close to each other. When describing the reassembly with an adjusted and the regeneration specific characteristics considering supply diagram the influence of capacity synchronization options on the logistic performance can be evaluated and help the service providers to design their supply chains. The main key figure will be the disrupted
WIP. Next to that, several other key figures can directly be derived from the supply diagram such as completion possibilities, the monetary evaluation of disrupted WIP and schedule adherences.

\section{Conclusions}

Capacity synchronization is an indispensable planning and control task for regeneration service providers in order to guarantee a high logistical performance and to meet the customer's demands in terms of on-time deliveries. Several options of how to synchronize workload and capacities exist. The synchronizing options can be applied for long-term, medium-term and short-term planning horizons. Each option influences the logistic performance of the entire supply chain as they have an influence on the processes' schedule deviation. Within the regeneration the reassembly process plays an important role as different material flows come together here. It is because the chosen capacity synchronization option has a direct impact on the supply processes' logistic performance, it is necessary to find a configuration of capacity synchronization options that leads to an optimized supply situation at the reassembly. The supply diagram is an adequate tool for regeneration service providers to evaluate different configurations of capacity synchronization options. The evaluation can be used for a general design of the entire regeneration supply chain.

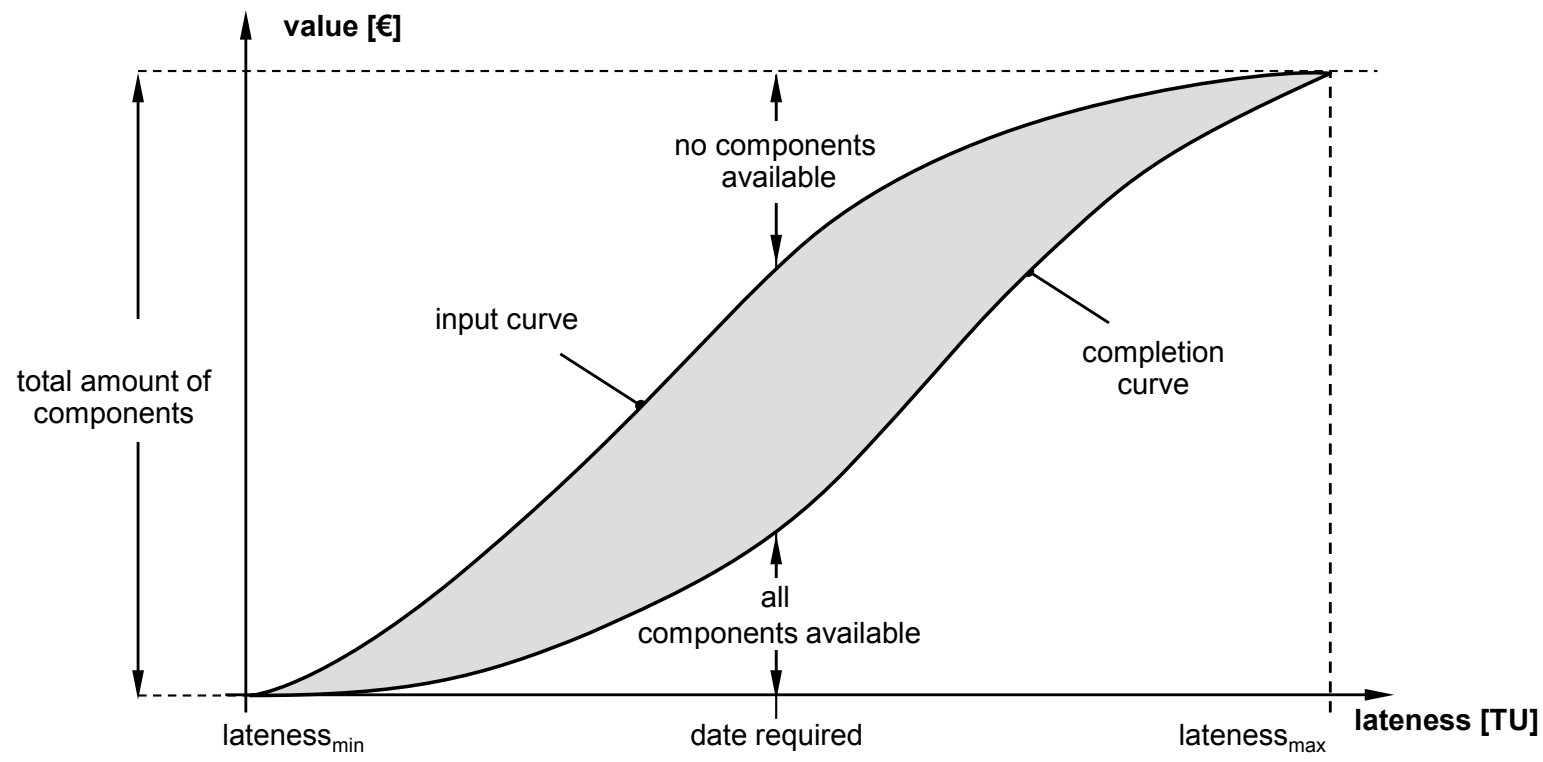

Figure 3. Supply diagram for the evaluation of capacity synchronization options (according to [3]) 


\section{Acknowledgment}

The authors would like to thank the German Research Foundation (DFG) for funding Collaborative Research Center 871 "Regeneration of complex capital goods" which is currently being conducted at the Leibniz Universität Hannover.

\section{REFERENCES}

[1] Eickemeyer, S. C., Busch, J., Heinke, Y., Goßmann, D. (2012). Verfügbarkeitsoptimierung in der Kapazitätsplanung. Zeitschrift für wirtschaftlichen Fabrikbetrieb, Jahrg. 107 (2012), pp. 903-907.

[2] Guide, V.D.R. (2000). Production planning and control for remanufacturing: industry practice and research needs. Journal of Operations Management 18 (2000), pp. 467-483.

[3] Beck, S. (2013). Modellgestütztes Logistikcontrolling konvergierender Materialflüsse. Dissertation Leibniz Universität Hannover, Garbsen: Berichte aus dem IFA.

[4] Eickemeyer, S. C.; Nyhuis, P. (2010). Capacity planning and coordination with fuzzy load information. The Business Review Cambridge, vol. 16, no. 1, pp. 259-264.

[5] Eickemeyer, C. S.; Krüger, C., Nyhuis, P. (2010). Kapazitätsplanung und -abstimmung bei unscharfen Belastungsinformationen. Zeitschrift für wirtschaftlichen Fabrikbetrieb, Jahrg. 105 (2010), pp. 323-427.

[6] Kellenbrink, C. et al. (2014). Planning the regeneration processes of complex capital goods. New Production
Technologies in Aerospace Industry, Procedia CIPR 24 (2014), pp. 140-145.

[7] Herde, F. (2013). Rahmenbedingungen der industriellen Regeneration von zivilen Flugzeugtriebwerken. Verlag BoD - Books on Demand, Norderstedt.

[8] Steinhilper, R. 1999. Produktrecycling. Vielfachnutzen durch Mehrfachnutzung. IRB Verlag, Stuttgart.

[9] Guide, V.D.R.; Kraus, M.E.; Srivastava, R. (1997). Scheduling policies for remanufacturing, International Journal of Production Economics. Bd. 48, Nr. 2, pp. 187-204.

[10] Stölting, W. (2006). Lebenszyklusorientierte strategische Planung von Remanufacturing-Systemen für elektr(on)isch Investitionsgüter. Fortschritt-Berichte VDI, VDI-Verlag $\mathrm{GmbH}$, Düsseldorf.

[11] Eickemyer, C.S.; Nyhuis, P. (2010). Capacity Planning and Coordination with Fuzzy Load Information. The Business Review, Cambridge, Vol. 16, Num. 1.

[12] Kuprat, T.; Nyhuis, P. (2015). Konfiguration von regenerationsspezifischen Gestaltungsoptionen. Zeitschrift für wirtschaftlichen Fabrikbetrieb, Jahrg. 110 (2015), pp. 277-280.

[13] Wiendahl, H.-P. (2010). Betriebsorganisation für Ingenieure. 7. Aufl., Carl Hanser Verlag, München.

[14] Berkholz, D. (2012). Grundmodell zur Kapazitätsabstimmung eines Arbeitssystems in der Regeneration. Dissertation Leibniz Universität Hannover, Garbsen: Berichte aus dem IFA.

[15] Breithaupt, J.-W. (2000). Rückstandorientierte Produktionsregelung von Fertigungsbereichen. Dissertation Leibniz Universität Hannover, Düsseldorf: Fortschritt-Berichte VDI. 